\title{
Looking into the crystal ball: biomarkers for outcomes of $\mathrm{HBV}$ infection
}

\author{
Hung-Chih Yang ${ }^{1,2,3} \cdot$ Jia-Horng Kao ${ }^{2,3,4}$
}

Received: 31 October 2015/ Accepted: 11 December 2015/Published online: 5 January 2016

(C) Asian Pacific Association for the Study of the Liver 2016

Chronic hepatitis B virus (HBV) infection exhibits complex host-virus interactions, leading to distinctive clinical features at different disease stages. The natural history of HBV acquired in the perinatal period or childhood can be divided into four chronological phases: immune tolerance (IT), immune clearance (IC), inactive carrier or lowreplication (LR) and reactivation or HBeAg-negative hepatitis $(\mathrm{ENH})$ [1]. Liver cirrhosis and hepatocellular carcinoma (HCC) are the long-term detrimental consequences of chronic HBV infection. The risk of chronic hepatitis B (CHB) patients for the development of end-stage liver disease is as high as $40 \%$ in the lifetime [2]. The main driving force for disease progression is the viral replication and immune-mediated hepatic necroinflammation. Current guidelines recommend that antiviral therapy should be given to patients with active viral replication, hepatic necroinflammation and significant hepatic fibrosis, primarily for those at the IC or ENH phases [3]. Therefore, precise determination of the clinical phase of a given patient is important to provide timely antiviral therapy to improve long-term outcomes.

In our clinical practice, the serum HBV DNA level, presence or absence of $\mathrm{HBeAg}$, and the alanine

Jia-Horng Kao

kaojh@ntu.edu.tw

1 Department of Microbiology, National Taiwan University College of Medicine, Taipei, Taiwan

2 Graduate Institute of Clinical Medicine, National Taiwan University College of Medicine, Taipei, Taiwan

3 Department of Internal Medicine, National Taiwan University Hospital, Taipei, Taiwan

4 Hepatitis Research Center, National Taiwan University Hospital, Taipei, Taiwan aminotransferase (ALT) level are commonly utilized to identify the clinical phases of chronic HBV infection. However, these assays are not perfect, and the clinical phase may not be accurately determined in a small proportion of patients. For example, sometimes, the IT and IC phases cannot be correctly characterized in patients with elevation of ALT levels caused by other etiologies, such as non-alcoholic steatohepatitis (NASH) or drug-induced liver injury (DILI). Likewise, the LR and ENH phases are somewhat difficult to distinguish, particularly in those with fluctuating ALT levels and long intervening remission periods. Therefore, novel HBV serological assays are necessary to better define the clinical phases of CHB patients.

In this issue, Wang et al. [4] compared three quantitative HBV serological markers, HBsAg, HBeAg and Hepatitis B core antibody (anti-HBc) levels, as well as HBV DNA levels to differentiate the clinical phases of Chinese CHB patients. In this cross-sectional study, they found that HBsAg level gradually declined as the disease proceeds through the IT, IC and eventually LR phases, but rebounded after reactivation in ENH phase. Both HBsAg and HBeAg levels are lower in the IC phase than in the IT phase, and have a good predictive value in the differentiation of IT from IC [the area under the receiver operating characteristic curve (AUROC) of HBsAg and HBeAg at the cutoff values of $4.41 \log _{10} \mathrm{IU} / \mathrm{mL}$ and $1118.96 \mathrm{~S} / \mathrm{CO}$ : 0.984 and 0.828 , respectively]. Both HBsAg and anti-HBc levels have a moderate predictive value for the differentiation of the LR and ENH phases (AUROCs of HBsAg and anti-HBc at cutoff values of $3.4 \log _{10} \mathrm{IU} / \mathrm{mL}$ and 10.5 S/CO: 0.796 and 0.705 , respectively). Their results demonstrated that these quantitative serological markers were complementary to HBV DNA levels and help define the clinical phases of CHB more precisely. 
Quantification assays are theoretically more informative than qualification ones. The role of HBV DNA levels in the natural history and risk of liver cirrhosis and HCC have been recognized in the community-based REVEAL-HBV cohort study in Taiwan [5, 6]. Recent studies have also shown the important role of HBsAg quantification in the natural history of CHB. HBsAg levels evolve along with the natural courses of CHB [7]. The HBsAg level is highest in the IT phase and starts to decline from the entry of the IC phase toward an LR phase, unless reactivation of $\mathrm{HBV}$ occurs. A previous study on the HBsAg kinetics of HBeAg-negative CHB patients showed that the HBsAg level was weakly correlated with the HBV DNA level. Significant HBsAg reduction was only observed in patients with undetectable HBV DNA [8]. Another study reported that, in an Italian cohort of 209 untreated and asymptomatic $\mathrm{HBeAg}$-negative genotype D carriers, the combination of single-point quantification of HBsAg $(<1000 \mathrm{IU} /$ $\mathrm{mL})$ and HBV DNA $(<2000 \mathrm{IU} / \mathrm{mL})$ could more accurately identify a 3-year inactive carrier state [9]. Our previous study demonstrated that, compared to the HBV DNA level, the HBsAg level is a better predictor for HBsAg loss in spontaneous $\mathrm{HBeAg}$ seroconverters [10]. Consistently, a large case-control study on Chinese CHB patients also reported that serum $\mathrm{HBsAg}<200 \mathrm{IU} / \mathrm{mL}$ and $0.5-\mathrm{log}$ reduction in HBsAg could predict HBsAg seroclearance within 3 years [11]. In addition, in patients with low viremia $(<2000 \mathrm{IU} / \mathrm{mL})$, the higher HBsAg level ( $>1000 \mathrm{IU} /$ $\mathrm{mL}$ ) is associated with the risk of disease progression, including hepatitis flares, ENH, liver cirrhosis and HCC $[12,13]$. In patients with low viremia $(<2000 \mathrm{IU} / \mathrm{mL})$ (Taiwanese patients with HBV genotype $\mathrm{B}$ or $\mathrm{C}$ infection), HBsAg $<1000 \mathrm{IU} / \mathrm{mL}$ can identify a subgroup of minimal-risk HBV carriers with an annual HCC incidence of $0.06 \%$. Moreover, the role of quantitative HBsAg levels in the development of liver cirrhosis and HCC has been validated in the REVEAL-HBV cohort study. In addition, the new risk prediction models of cirrhosis and HCC have excellent prediction accuracy by the integration of $\mathrm{HBsAg}$ levels and other host and HBV profiles [14].

Hepatitis B core antigens induce strong immune responses during $\mathrm{HBV}$ infection. IgG anti-HBc persists lifelong in individuals with prior exposure to HBV, even in those who have recovered from acute hepatitis B for many years. However, the characteristics of total anti-HBc levels during CHB remain unclear. A recent study showed that quantitative total anti-HBc levels were positively correlated with ALT levels in CHB patients [15]. In addition, anti-HBc levels vary at different clinical phases [16]: higher in an inflammatory state, including the IC and ENH phases, but lower in the IT and LR phases. Although CHB patients at the IT phase have very high levels of HBV DNA, their anti-HBc levels are comparable to those at the
LR phase. Surprisingly, in the Chinese cohort, Wang et al. [4] (this issue) showed that CHB patients at the LR phase have anti-HBc levels similar to those at the IC phase, but higher than those at the IT and ENH phases. It remains unclear what causes this discrepancy. One plausible explanation is that they used a semi-quantitative assay rather than a genuine quantitative assay with the standardized international unit (IU). Collectively, the total anti$\mathrm{HBc}$ level may serve as a promising serological marker for HBV-induced liver disease. Compared to the ALT level, the anti-HBc level has less fluctuation in ENH patients. In addition, the anti-HBc level is complementary to current quantitative viral markers, including the HBsAg level and the HBV DNA level. The HBsAg level may reflect the transcription activity of HBV covalently closed circular DNA (cccDNA), whereas the anti-HBc level represents the host antiviral immune responses against the HBV core protein. The role of total anti-HBc level in predicting the long-term outcomes of $\mathrm{CHB}$ patients deserves further investigation.

Hepatitis B core-related antigen (HBcrAg), consisting of HBV core antigen ( $\mathrm{HBcAg}$ ), hepatitis $B$ e antigen ( $\mathrm{HBeAg}$ ), and the 22-kDa precore protein (p22cr), has been suggested as an additional marker of CHB. HBcrAg has been shown to correlate other virological markers, including serum HBV DNA and intrahepatic cccDNA, so can serve a marker for disease activity and treatment response [17]. In addition, in a large European cohort predominantly infected with genotypes A and D, $\mathrm{HBcrAg}$ varied significantly in different phases of $\mathrm{CHB}$. $\mathrm{HBcrAg}$ was high in the IT and IC phases, lower in the ENH phase, and lowest in the LR phase [18]. A large longitudinal cohort is required to further explore the role of HBcrAg as a marker for the long-term outcomes of CHB.

Considering the heterogeneous nature and clinical outcomes of $\mathrm{CHB}$, precise definition of clinical phases of patients is the prerequisite to provide better medical care. A combination of existing and upcoming biomarkers may help to more accurately determine the clinical phases of chronic HBV infection. With the development of novel quantitative serological markers, we are confident in being able to refine the definition of each clinical phase. Moreover, we may further identify the subgroup of patients at risk. This has been exemplified by the story of HBsAg quantification, showing that a combination of HBV DNA level $<2000 \mathrm{IU} / \mathrm{mL}$, normal ALT level and HBsAg level $<1000 \mathrm{IU} / \mathrm{mL}$ can define minimal-risk HBV carriers [9].

In conclusion, the traditional natural history of CHB should be revisited with new quantitative serological or even immunological markers. The predictive value of combining these biomarkers in long-term clinical outcomes, including the risk of liver cirrhosis and HCC, should be scrutinized in a larger prospective cohort of 
patients with different HBV genotype infections from different parts of the world.

\section{References}

1. Kao JH, Chen DS. Global control of hepatitis B virus infection. Lancet Infect Dis 2002;2:395-403

2. Lin CL, Kao JH. Perspectives and control of hepatitis B virus infection in Taiwan. J Formos Med Assoc 2015;114:901-909

3. European Association For The Study Of The Liver. EASL clinical practice guidelines: management of chronic hepatitis B virus infection. J Hepatol 2012;57:167-185

4. Wang L, Zou ZQ, Wang K, Yu JG, Liu XZ. Role of serum hepatitis $B$ virus marker quantitation to differentiate natural history phases of HBV infection. Hepatol Int. 2016. doi:10.1007/ s12072-015-9657-6

5. Chen CJ, Yang HI, Su J, Jen CL, You SL, Lu SN, et al. Risk of hepatocellular carcinoma across a biological gradient of serum hepatitis B virus DNA level. JAMA 2006;295:65-73

6. Iloeje UH, Yang HI, Su J, Jen CL, You SL, Chen CJ. Predicting cirrhosis risk based on the level of circulating hepatitis B viral load. Gastroenterology 2006;130:678-686

7. Chan HL, Wong VW, Wong GL, Tse CH, Chan HY, Sung JJ. A longitudinal study on the natural history of serum hepatitis B surface antigen changes in chronic hepatitis B. Hepatology 2010;52:1232-1241

8. Seto WK, Wong DK, Fung J, Hung IF, Yuen JC, Tong T, et al. Serum hepatitis B surface antigen (HBsAg) kinetics in hepatitis B e antigen ( $\mathrm{HBeAg}$ )-negative chronic hepatitis B. Hepatol Int 2012;7:119-126

9. Brunetto MR, Oliveri F, Colombatto P, Moriconi F, Ciccorossi P, Coco B, et al. Hepatitis B surface antigen serum levels help to distinguish active from inactive hepatitis $\mathrm{B}$ virus genotype D carriers. Gastroenterology 2010;139:483-490
10. Tseng TC, Liu CJ, Su TH, Wang CC, Chen CL, Chen PJ, et al. Serum hepatitis B surface antigen levels predict surface antigen loss in hepatitis B e antigen seroconverters. Gastroenterology 2011;141:517-525

11. Seto WK, Wong DK, Fung J, Hung IF, Fong DY, Yuen JC, et al. A large case-control study on the predictability of hepatitis B surface antigen levels three years before hepatitis B surface antigen seroclearance. Hepatology 2012;56:812-819

12. Tseng TC, Liu CJ, Yang HC, Su TH, Wang CC, Chen CL, et al. High levels of hepatitis B surface antigen increase risk of hepatocellular carcinoma in patients with low HBV load. Gastroenterology 2012;142:1140-1149

13. Tseng TC, Liu CJ, Yang HC, Su TH, Wang CC, Chen CL, et al. Serum hepatitis B surface antigen levels help predict disease progression in patients with low hepatitis B virus loads. Hepatology 2013;57:441-450

14. Lee MH, Yang HI, Liu J, Batrla-Utermann R, Jen CL, Iloeje UH, et al. Prediction models of long-term cirrhosis and hepatocellular carcinoma risk in chronic hepatitis B patients: risk scores integrating host and virus profiles. Hepatology 2013;58:546-554

15. Yuan Q, Song LW, Liu CJ, Li Z, Liu PG, Huang CH, et al. Quantitative hepatitis B core antibody level may help predict treatment response in chronic hepatitis B patients. Gut 2013;62: 182-184

16. Song LW, Liu PG, Liu CJ, Zhang TY, Cheng XD, Wu HL, et al. Quantitative hepatitis B core antibody levels in the natural history of hepatitis B virus infection. Clin Microbiol Infect 2015;21: 197-203

17. Wong DK, Tanaka Y, Lai CL, Mizokami M, Fung J, Yuen MF. Hepatitis B virus core-related antigens as markers for monitoring chronic hepatitis B infection. J Clin Microbiol 2007;45:39423947

18. Maasoumy B, Wiegand SB, Jaroszewicz J, Bremer B, Lehmann $\mathrm{P}$, Deterding K, et al. Hepatitis B core-related antigen ( $\mathrm{HBcrAg}$ ) levels in the natural history of hepatitis B virus infection in a large European cohort predominantly infected with genotypes A and D. Clin Microbiol Infect 2015;21:e1-e10 